\title{
Research on Thermal Insulation Performance of Lightweight Thermal Protection Materials for High Speed Aircraft under Different Boundary Conditions
}

\author{
Feng Wang, Dafang $\mathrm{Wu}^{\mathrm{a}}$ and Haoyuan Ren \\ School of Aeronautic Science and Engineering, Beihang University, Beijing 100191, China
}

\begin{abstract}
The determination of thermal insulation performance of thermal protection materials or structures is an indispensable and important step in the safety design of high speed flight vehicles. To obtain the temperature difference of the radiating surface for plate specimens under three different boundary conditions in heat insulation experiments (the specimens were placed either vertically or horizontally with the radiating surface facing down or horizontally with the radiating surface facing up), three thermal test setups were established to test the thermal insulation performance of light-weight ceramic specimens at different temperatures. The results show that the radiating surface temperature was the highest when the specimen was placed horizontally with the radiating surface facing down, while it was the lowest when the specimen was placed horizontally with the radiating surface facing up.The numerical calculation results agreed very well with the experimental ones, confirming the credibility and accuracy of the experimental results. The different thermal insulation performances of the plate specimens obtained under three different boundary conditions will provide important guidance for designers in the design of thermal protection systems for large cabins of high speed flight vehicles.
\end{abstract}

\section{Introduction}

With the continuous improvement of design speed for hypersonic vehicles, the high temperature environment resulting from aerodynamic heating becomes more and more harsh. Therefore, it is imperative to implement thermal protection measures to protect equipment inside the vehicles and ensure their safe operation. Because of the strict restriction on the weight and thickness of the thermal insulation materials, light-weight and high-efficiency thermal insulation materials are required to construct a thermal protection system. The determination of thermal insulation performance of thermal protection materials or structures is an indispensable and critical step in the safety design of high-speed flight vehicles. Therefore, the experimental investigation of thermal protection materials in high-temperature environments is receiving increasing attention. Based on the experimental results of the thermal insulation performance of $\mathrm{ZrO}_{2}$ ceramic fiber materials, J.J. Sun and Z.J. Hu et al.[1] analyzed the effect of sintering temperature, binder contents and other factors on the microstructure, linear shrinkage and thermodynamic properties of highly porous ceramic fiber materials and, thus, optimized the chemical composition and preparation process for the thermal insulation material. By

a Corresponding author : wdf1950@163.com 
measuring the thermal conductivity of $\mathrm{Al}_{2} \mathrm{O}_{3}$ nanomaterials at different temperatures using the transient plane source method, J.N. Li and Z.J. Hu et al.[2]. investigated the high-temperature thermal insulation performance of $\mathrm{Al}_{2} \mathrm{O}_{3}$ nanomaterial sheets and their thermal stability. Based on the results of the thermal insulation experiments of porous wet-lay plate materials in high temperature environments, R. Figueiredo and J.J. Costa et al.[3] explored the effect of water content on the thermal protection performance of the porous material. Based on the aerodynamic heating numerical simulation and experimental test of a metallic honeycomb plate structure and by taking into account the coupling of heat conduction and radiation, Chen and Gao et al.[4] established a finite element model for the heat conduction of a metallic honeycomb plate and obtained the temperature distribution of the metallic honeycomb plate structure along the thickness direction in high temperature environments. Qing and Jiang et al.[5] built a quartz lamp-based infrared heating device to investigate the thermal insulation performance of plate-type thermal protection components in high speed flight vehicles. Because there are no experimental setups for the thermal insulation performance of hightemperature plate materials or structures with uniform regulations on the market, researchers normally need to customize experimental systems for the simulation of aerothermodynamic experiments[6-11]. In the cabin structure of high-speed flight vehicles as shown in Figure 1, the directions of the radiating surfaces of the internal walls of the cabin are different. Thermal insulation performance experiments of plate materials or structures need to be simplified to the following three different experimental modes: (1) the specimen is placed vertically; (2) the specimen is placed horizontally with the radiating surface facing down; and (3) the specimen is placed horizontally with the radiating surface facing up. For the different thermal test modes, the boundary conditions of the specimens are also different. In fact, for the heat insulation experiments at high temperatures, researchers often only use one of the three modes. Among the three experimental modes, when the temperature of the radiating surface is the same, which mode has the highest radiating surface temperature? Moreover, which mode has a lower radiating surface temperature? What is the difference? These questions are very important to designers in the design of thermal protection systems for high-speed flight vehicles and the test scheme.
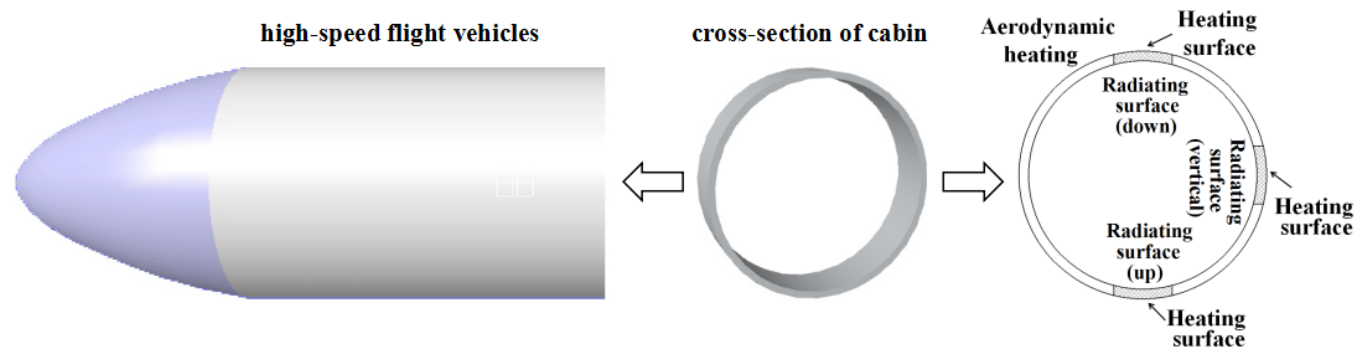

Figure 1. Schematic of the heating of the cabin structure in a high speed flight vehicle

Based on the three different thermal boundary conditions in the thermal insulation experiments of the plate materials, the corresponding experimental setups were established: the specimen was placed vertically; the specimen was placed horizontally with the radiating surface facing down; the specimen was placed horizontally with the radiating surface facing up. Test equipment with different heating directions were used for testing the thermal insulation performance of light-weight ceramic specimens to obtain the radiating surface temperatures of the plate specimens at different boundary conditions. In addition, numerical simulation was also performed to calculate the thermal insulation properties of light-weight ceramic materials. The calculation results were compared to experimental ones to confirm the credibility and accuracy of the experimental results.

\section{Thermal insulation test under different boundary conditions}

\subsection{Specimen}

A light-weight porous ceramic material specimen is shown in Figure 2. It is mainly composed of $\mathrm{Al}_{2} \mathrm{O}_{3}$ and $\mathrm{SiO}_{2}$ particles. This material has characteristics such as high-temperature resistance, low 
thermal conductivity, corrosion resistance, high strength and high hardness. The X \& Y dimensions of the specimen are $150 \mathrm{~mm} \times 150 \mathrm{~mm}$, and the thickness is $20 \mathrm{~mm}$. The density and porosity of the material are $330 \mathrm{~kg} / \mathrm{m}^{3}$ and $85 \%$, respectively.

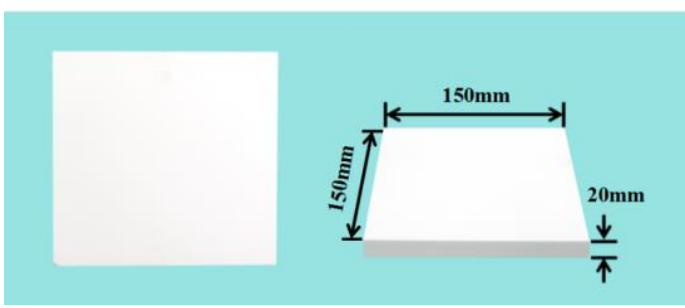

Figure 2. A specimen of the light-weight ceramic material

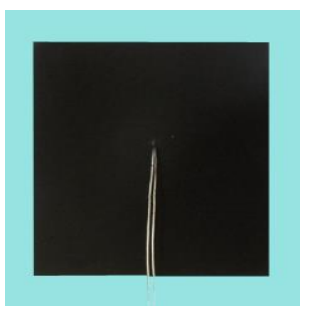

Figure 3. Thin metal plate

\subsection{Measurement of the radiating surface temperature}

For some light-weight thermal insulation materials such as ceramic fiber blanket, nanomaterials, and porous ceramic materials because of their high porosity, it is very difficult to blacken the heating surfaces. Because the surfaces of these materials are soft, it is difficult to keep the installed temperature sensors in place in high temperature environments. To accurately measure and control the radiating surface temperature of the light-weight fiber blanket, nanomaterials or porous ceramic materials, a high-temperature thin metal plate (1 mm thickness) as shown in Figure 3 can be firmly pressed on the heating surface of the specimen. The surface of the metal plate was blackened to reduce the undesired impact of local grayscale variation on the surface in high temperature environments on the uniformity of the temperature field of the heating surface. In this paper, to understand the impact of the addition of 1-mm-thick thin metal plate on the heating surface temperature of the ceramic specimen, a verification test was performed. First, temperature sensors were installed in the center of the front and back surfaces of the thin metal plate. A $20 \mathrm{~mm}$ thick soft ceramic heat insulation material was installed on the outside of the back surface. A computer automatic control system was used to control the front-surface temperature of the metal plate[12] in real-time and measure the backsurface temperature of the metal plate. Figure 4 and Table 1 show the set temperature and the actual control temperature of the front surface of the 1-mm-thick thin metal plate, and the back-surface temperature of the metal plate. It can be seen from Figure 4 that the difference in the temperatures of the front and back surfaces of the metal plate was very small. It can be seen from the data in Table 1 that in the temperature ascending stage, the relative error of the front and back surface temperatures of the metal plate was less than $1.6 \%$. When the temperature entered the stable stage, the relative error of the front and back surface temperatures of the metal plate was within $0.2 \%$. Therefore, the addition of the 1-mm-thick thin metal plate has very little impact on the heating surface temperature of the lightweight ceramic specimen.

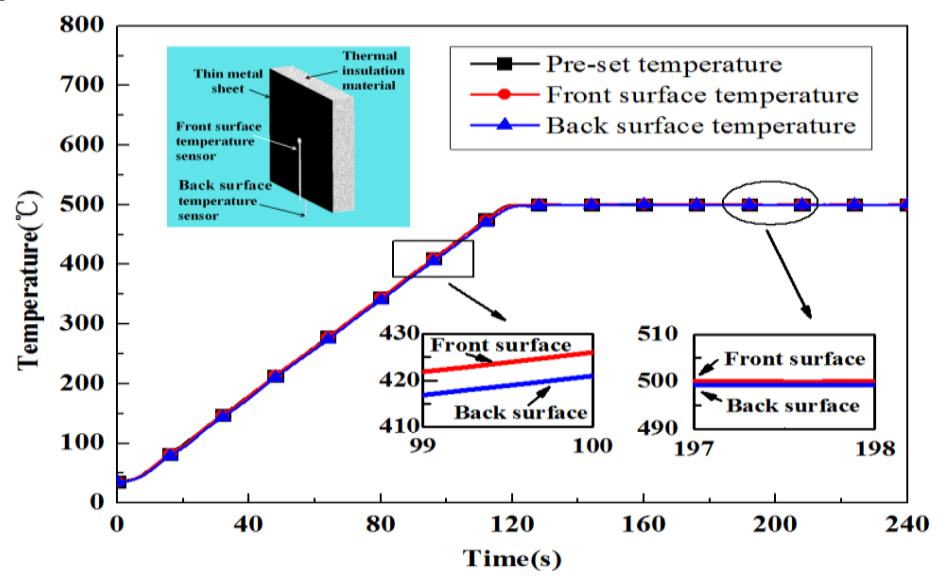


Figure 4. Measured front and back surface temperatures of the 1-mm-thick metal plate

Table 1. Front and back surface temperatures, and the relative error of the 1-mm-thick metal plate

\begin{tabular}{lcccccccc}
\hline Time $/ \mathrm{s}$ & 0 & 60 & 90 & 120 & 150 & 180 & 210 & 240 \\
\hline Pre-set temperature $/{ }^{\circ} \mathrm{C}$ & 35.0 & 262.3 & 385.2 & 500.0 & 500.0 & 500.0 & 500.0 & 500.0 \\
Front-surface $/{ }^{\circ} \mathrm{C}$ & 35.3 & 261.8 & 386.0 & 499.4 & 500.9 & 500.2 & 500.5 & 500.9 \\
Back-surface $/{ }^{\circ} \mathrm{C}$ & 35.0 & 257.6 & 381.2 & 496.2 & 500.1 & 499.4 & 499.7 & 500.0 \\
Difference $/{ }^{\circ} \mathrm{C}$ & 0.3 & 4.2 & 4.8 & 3.2 & 0.8 & 0.8 & 0.8 & 0.9 \\
Relative error $/ \%$ & 0.9 & 1.6 & 1.2 & 0.6 & 0.2 & 0.2 & 0.2 & 0.2 \\
\hline
\end{tabular}

\subsection{Thermal boundaries of the specimen}

Figure 5 shows the schematic of the natural convection heat transfer of the radiating surface under three different boundary conditions in the heat insulation performance tests for the plates, and the picture of the quartz lamp-based radiation heating tests. Figure 5(a) shows the vertically placed specimen; Figure 5(b) shows the horizontally placed specimen with the radiating surface facing down; Figure 5(c) shows the horizontally placed specimen with the radiating surface facing up. To obtain a uniform temperature field, the quartz lamp heating arrays were densely arranged with an inter-lamp spacing of approximately 3-5 $\mathrm{mm}$. The distance between the heating source and the plate specimen was approximately $100 \mathrm{~mm}$. The radiating surface of the specimen has an open style.
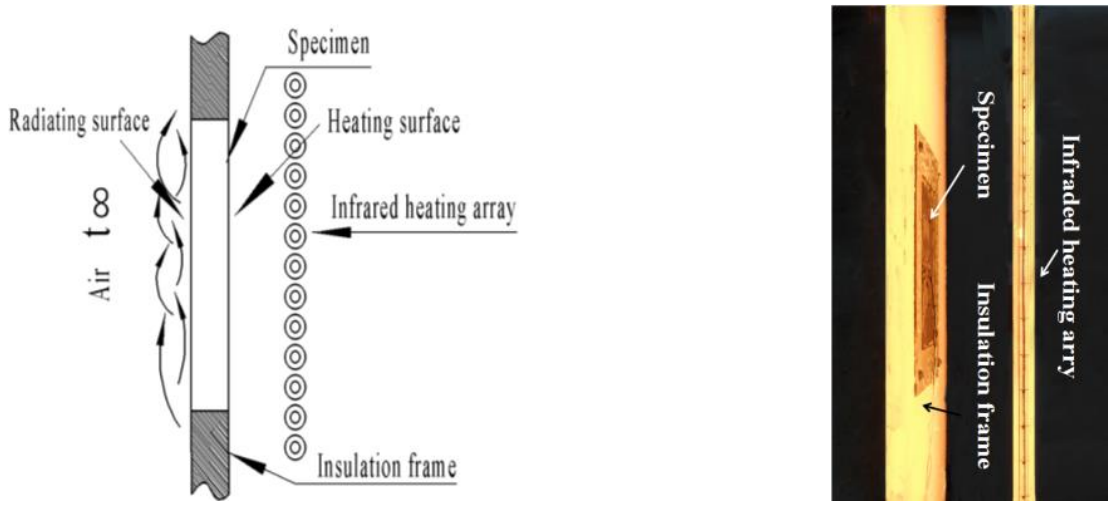

(a) Vertically placed
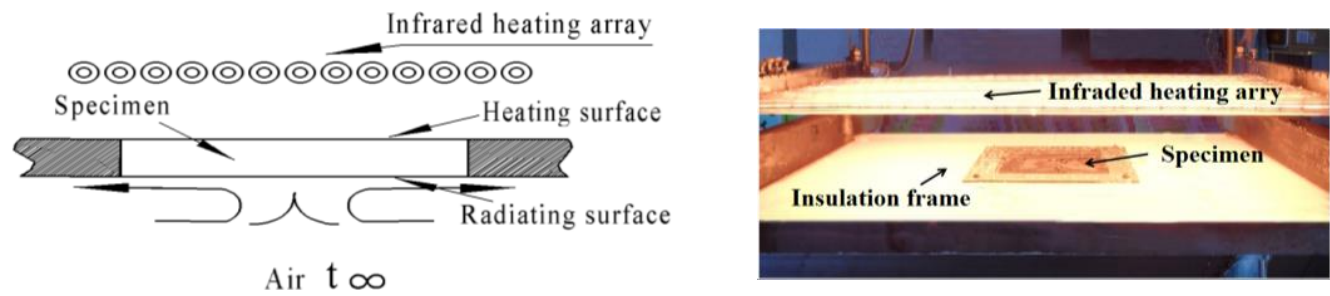

(b) Horizontally placed with the radiating surface facing down

Air $\mathrm{t} \infty$

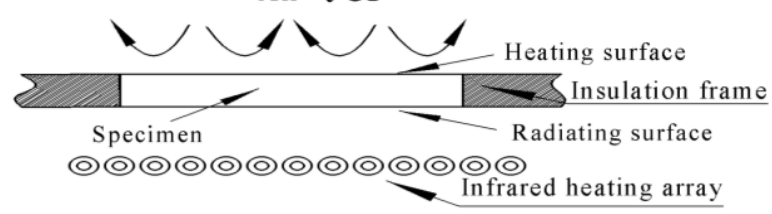

(c) Horizontally placed with the radiating surface facing up

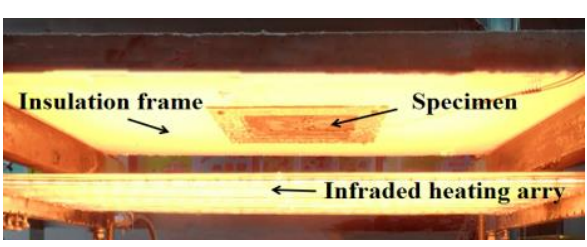


Figure 5. The three installation modes for the plate tests

\subsection{Test temperature}

In testing the thermal insulation of the light-weight ceramic materials, different temperature conditions were set as shown in Figure $6\left(1,000{ }^{\circ} \mathrm{C}, 800{ }^{\circ} \mathrm{C}, 600{ }^{\circ} \mathrm{C}, 400{ }^{\circ} \mathrm{C}\right.$ and $\left.200{ }^{\circ} \mathrm{C}\right)$. The heating process is as follows: the thermal control system heated the heating surface of the specimen to the set temperature in 60 seconds and then maintained the heating surface temperature constant; the duration of the whole heating process was 1,800 seconds. The temperature curves in Figure 6 show the excellent agreement between the measured temperature and the set temperature. Table 2 lists the set temperature and measured temperature values of the specimen when the steady-state temperature was $1,000{ }^{\circ} \mathrm{C}$. It can be seen from Table 2 that in the whole heating process, the relative error between the set temperature and actual control temperature was less than $1 \%$, indicating that this test system can very well simulate steady-state or dynamic thermal environments.

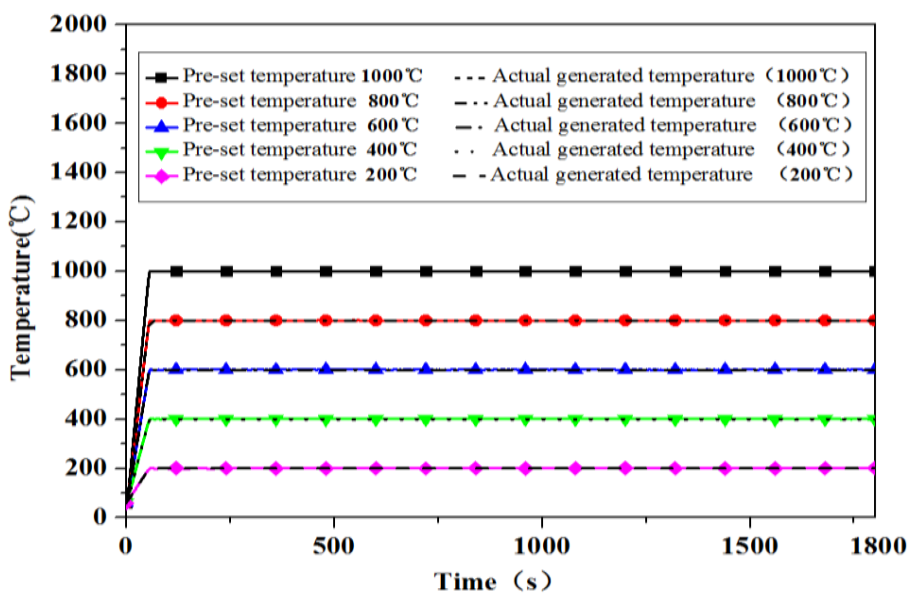

Figure 6. Set temperature and actual control temperature curves of the specimen (vertically placed)

Table 2. Set and actual values of the heating surface temperatures for the light-weight ceramic materials

\begin{tabular}{ccccccccc}
\hline Time $/ \mathrm{s}$ & 25 & 50 & 300 & 600 & 900 & 1200 & 1500 & 1800 \\
\hline Pre-set temperature $/{ }^{\circ} \mathrm{C}$ & 389.6 & 921.1 & 1000.0 & 1000.0 & 1000.0 & 1000.0 & 1000.0 & 1000.0 \\
Controlled temperature $/{ }^{\circ} \mathrm{C}$ & 391.3 & 917.5 & 1002.4 & 1001.2 & 1000.2 & 1000.2 & 1000.4 & 1000.2 \\
Difference $/{ }^{\circ} \mathrm{C}$ & 1.7 & 3.6 & 2.4 & 1.2 & 0.2 & 0.2 & 0.4 & 0.2 \\
Relative error $/ \%$ & 0.44 & 0.39 & 0.24 & 0.12 & 0.02 & 0.02 & 0.04 & 0.02 \\
\hline
\end{tabular}

\subsection{Test results}

Figure 7 shows the heat insulation results for the light-weight ceramic materials under three different boundary conditions when the heating surface temperature was $1,000{ }^{\circ} \mathrm{C}, 800{ }^{\circ} \mathrm{C}, 600{ }^{\circ} \mathrm{C}$ and $400{ }^{\circ} \mathrm{C}$, respectively (because of overlap, the test results for the heating surface temperature of $200{ }^{\circ} \mathrm{C}$ were omitted). It can be seen from Figure 7 that for the different heating modes, even when the heating surface temperatures were the same, the radiating surface temperatures would be different. The radiating surface temperature of the Horizontally placed specimen with the radiating surfacefacing up (Figure (a)) was lower than that of the vertically placed specimen (Figure (b)). The radiating surface temperatures of the modes in Figure (b) and (c) were close.

To further compare the heat insulation results of the light-weight ceramic materials under three different boundary conditions, Figure 8 shows the heating surface temperature curves of the specimens when the radiating surface temperature was $1,000^{\circ} \mathrm{C}, 800^{\circ} \mathrm{C}$ or $200^{\circ} \mathrm{C}$. In Figure 8 , the 
radiating surface temperature of the specimen for the three different modes was labeled as $\mathrm{Tv}, \mathrm{Td}$, and $\mathrm{Tu}$, where $\mathrm{TV}$ is the radiating surface temperature of the vertically placed specimen, $\mathrm{Td}$ is the temperature of the horizontally placed specimen with the radiating surface facing down, and $\mathrm{Tu}$ is the temperature of the horizontally placed specimen with the radiating surface facing up.

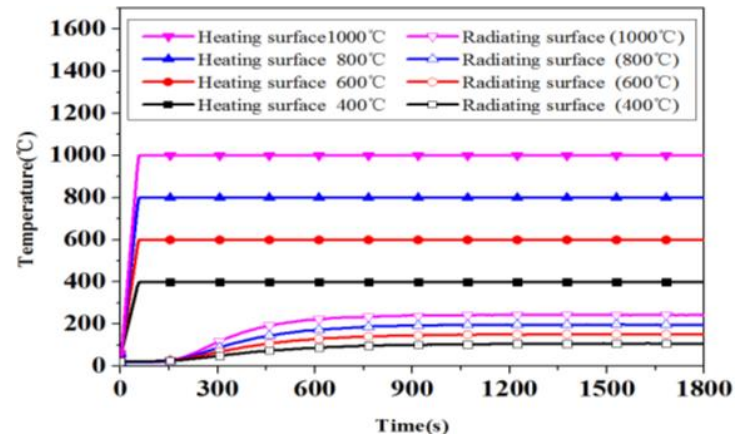

(a) Horizontally placed with the radiating surface facing up
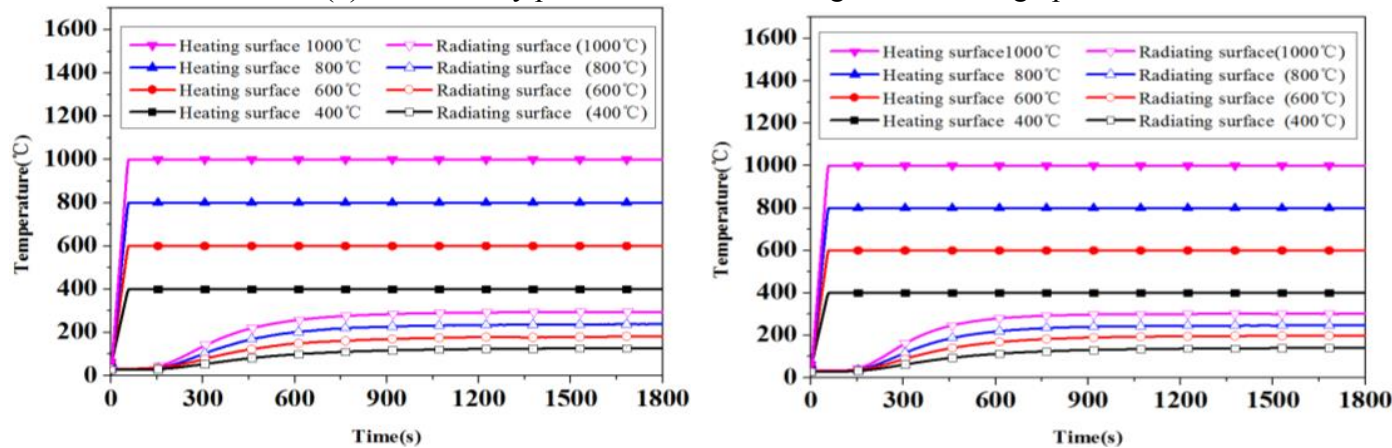

(b) Vertically placed

(c) Horizontally placed with the radiating surface facing down

Figure 7. Thermal insulation test results for the ceramic materials under three different boundary conditions

It can be seen from Figure 8 that among the three different thermal boundary conditions, Tu was significantly lower than $\mathrm{Td}$, and $\mathrm{Tv}$ was close to Td.Table 3 lists the radiating surface temperatures of the light-weight ceramic materials under three different boundary conditions when the heating surface temperature was $1,000^{\circ} \mathrm{C}$. It can be seen from Table 3 that at $1800 \mathrm{~s}, \mathrm{Td}$ was the highest $\left(301.6^{\circ} \mathrm{C}\right)$, and $\mathrm{Tu}$ was the lowest $\left(242.2^{\circ} \mathrm{C}\right.$ with a temperature difference of $59.4^{\circ} \mathrm{C}$ and a relative error of $19.7 \%$. This is because when the air near the radiating surface of the specimen was heated, its density decreased, and its volume increased. As a result, the hot air generated a lifting force. When the radiating surface of the plate specimen faced down, the ascending motion produced by the hot air was hindered, leading to the increase of heat accumulation on the specimen surface. As a result, the lost energy was less than the energy carried away by the hot air when the radiating surface of the specimen facedup.It can be seen from Table 3 that $\mathrm{Tv}$ is not much different from $\mathrm{Td}$ in that $\mathrm{Tv}$ is $2.3 \%$ lower than Td.

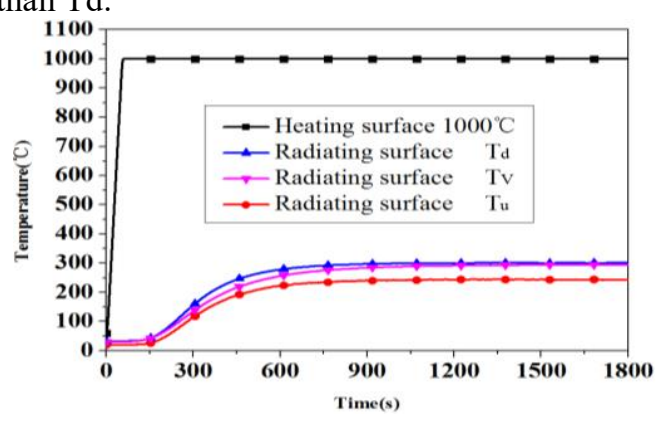

(a) Heating surface temperature of $1,000{ }^{\circ} \mathrm{C}$

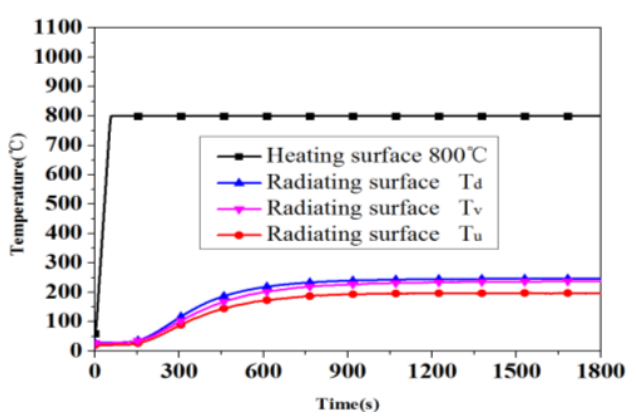

(b)Heating surface temperature of $800^{\circ} \mathrm{C}$ 


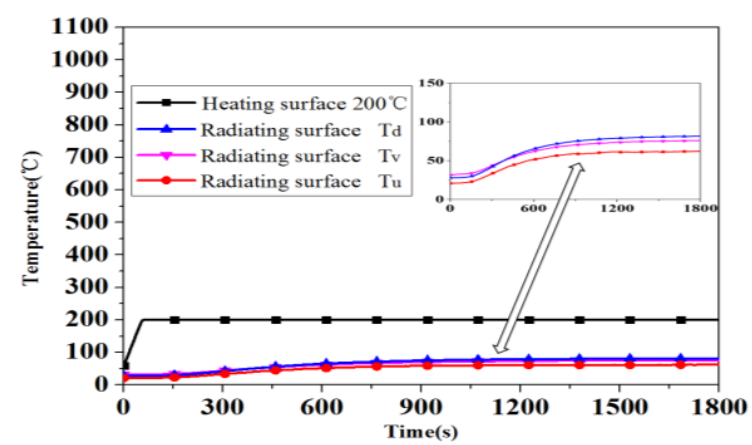

(c) Heating surface temperature of $200^{\circ} \mathrm{C}$

Figure 8. Thermal insulation effect of the ceramic specimen under three different boundary conditions

Table 3. Radiating surface temperatures of the ceramic plates under three different boundary conditions (heating surface temperature of $1,000^{\circ} \mathrm{C}$ )

\begin{tabular}{|c|c|c|c|c|c|c|c|c|c|}
\hline Time /s & 200 & 400 & 600 & 800 & 1000 & 1200 & 1400 & 1600 & 1800 \\
\hline Heating surface temperature $/{ }^{\circ} \mathrm{C}$ & 1000.0 & 1000.0 & 1000.0 & 1000.0 & 1000.0 & 1000.0 & 1000.0 & 1000.0 & 1000.0 \\
\hline Radiating surface temperature $\mathrm{Td} /{ }^{\circ} \mathrm{C}$ & 71.1 & 222.1 & 278.2 & 294.2 & 299.2 & 300.6 & 301.3 & 301.3 & 301.6 \\
\hline Radiating surface temperature $\mathrm{Tv} /{ }^{\circ} \mathrm{C}$ & 67.6 & 195.6 & 256.6 & 279.2 & 288.5 & 292.1 & 293.6 & 294.4 & 294.6 \\
\hline Radiating surface temperature $\mathrm{Tu} /{ }^{\circ} \mathrm{C}$ & 46.5 & 170.2 & 222.1 & 237.1 & 242.1 & 243.2 & 244.0 & 243.7 & 242.2 \\
\hline
\end{tabular}

\section{Numerical calculation}

\subsection{Finite element model}

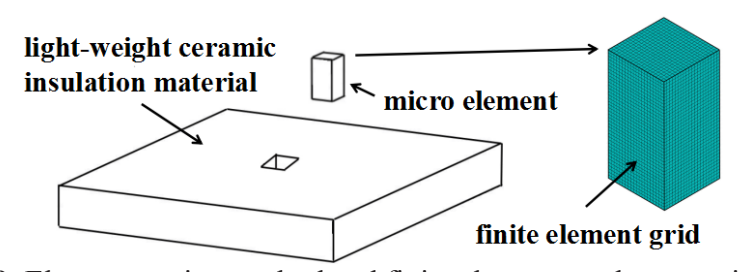

Figure 9. Element cutting method and finite element mesh generation

The finite element model as shown in Figure 9 was established for the numerical calculation of the thermal insulation performance of the plate materials at three different boundary conditions.A rectangular-shaped block with a size of $10 \mathrm{~mm} \times 10 \mathrm{~mm} \times 20 \mathrm{~mm}$ was cut from the center of the plate. The cut block was subjected to mesh partition using the 6-plane, 8-node and Solid70 element to generate 16,000 elements and 18,081 nodes. Assuming that the temperature variation of the model in the plane was small, there was no need to consider heat exchange within the plane. The heat was mainly transferred along the thickness direction and can be considered as one-dimensional, transient heat transfer. The temperature $\mathrm{T}(\mathrm{x}, \mathrm{t})$ along the thickness direction inside the material satisfies the following heat conduction equation in the Cartesian coordinate system[13]

$$
\rho c \frac{\partial T}{\partial t}=\frac{\partial}{\partial x}\left(k \frac{\partial T}{\partial x}\right)
$$

where $\rho$ is the density of the thermal insulation material, $\mathrm{k}$ is the thermal conductivity of the material, and $\mathrm{c}$ is the specific heat capacity of the material.The material parameters are the same as the lightweight ceramic specimen. This experiment only used one-side heating. Because the temperature along the thickness of the material was different, thermal conductivity and specific heat capacity at different temperatures were used in the calculation. Table 4 lists the specific heat capacity and thermal conductivity of the light-weight ceramic materials in the temperature range of $30-1200{ }^{\circ} \mathrm{C}$. 
Table 4. Physical parameters for the light-weight ceramic materials

\begin{tabular}{ccccccccccc}
\hline Temperature $/{ }^{\circ} \mathrm{C}$ & 30 & 100 & 200 & 300 & 400 & 500 & 600 & 700 & 900 & 1200 \\
\hline Thermal conductivity $\mathrm{W} /\left(\mathrm{m} \cdot{ }^{\circ} \mathrm{C}\right)$ & 0.05 & 0.055 & 0.061 & 0.069 & 0.076 & 0.082 & 0.09 & 0.098 & 0.113 & 0.138 \\
specific heat $\mathrm{J} /\left(\mathrm{kg} \cdot{ }^{\circ} \mathrm{C}\right)$ & 850 & 870 & 900 & 930 & 1050 & 1190 & 1230 & 1270 & 1370 & 1430 \\
\hline
\end{tabular}

\subsection{Boundary conditions}

Because the circumference of the light-weight ceramic specimen was installed with an insulation border, the circumferential boundary can be approximated as adiabatic. The boundary conditions of the rectangular-shaped block were mainly determined by the states of the front and back surfaces. Because the front surface temperature of the specimen was generated by the thermal control system based on pre-set values, the front surface temperature was a known value. Therefore, the boundary condition of the front surface is the Dirichlet boundary condition, i.e., the predefined temperature boundary condition. The heat transfer between the radiating surface of the specimen and outer space is mainly consisted of radiative heat transfer and natural convection. For the three different modes, there is little difference in the energy transfer due to radiation on the radiating surface. In contrast, the geometric distribution of the radiating surface has a decisive impact on the motion state of the fluid. The coefficient of the natural convection heat transfer for the radiating surface, $h$, can be calculated from the following equation

$$
h=\frac{N u \lambda}{H}
$$

where $\lambda$ is the thermal conductivity of air, $\mathrm{H}$ is the characteristic length of the light-weight ceramic specimen, and $\mathrm{Nu}$ is Nusselt number. $\mathrm{Nu}$ is determined by the experimental correlation of the natural convection heat transfer in the large space under the uniform wall temperature boundary condition:

$$
N u=C(G r P r)^{n}
$$

where Pr is the Prandtl number, and $\mathrm{C}$ and $\mathrm{n}$ are the constants determined by the air flow. Gr is the Grashof number and can be calculated from the equation below:

$$
G r=\frac{g \alpha\left(T_{w}-T_{\alpha}\right) H^{3}}{v^{2}}
$$

where $\alpha$ is the expansion coefficient of air, Tw is the back surface temperature, T $\alpha$ is the temperature of the external space, and $\mathrm{V}$ is the kinematic viscosity coefficient of air.

For the three corresponding modes in Equation (3), their constant $\mathrm{C}$ values that represent air flow states are different and related to Gr. When the specimen was vertically placed, the Grashof number (Gr) for the radiating surface of the specimen calculated at different temperatures ranged from $2.6 \times$ $106 \sim 2.4 \times 107$. The gas flow state in the natural convection of the radiating surface belongs to laminar flow. Therefore, $\mathrm{C}$ is 0.59 [13]. When the specimen was horizontally placed, the product of $\mathrm{Gr}$ and $\mathrm{Pr}$ calculated from Equation (4) at different temperatures ranged from $2.8 \times 104 \sim 2.6 \times 105$. For the vertically placed specimen, when its radiating surface faced up, $\mathrm{C}$ is 0.54 [14]; when its radiating surface faced down, $\mathrm{C}$ is $0.27[15]$.

\section{Comparison of the calculated and experimental results}

Figure 10 shows the comparison curves of the heat insulation performance from the calculated and experimental results for the light-weight ceramic plate under three different boundary conditions. It can be seen from Figure 10 that the calculated and experimental results agreed very well with each other under the three different boundary conditions. Table 3 lists the calculated value, experimental value and relative error of the radiating surface temperature when the heating surface temperature was $1,000{ }^{\circ} \mathrm{C}, 800{ }^{\circ} \mathrm{C}, 600{ }^{\circ} \mathrm{C}, 400{ }^{\circ} \mathrm{C}$ or $200{ }^{\circ} \mathrm{C}$. The results in Table 5 show that the relative error between the calculated and experimental values was less than $5 \%$. Therefore, the two had excellent agreement. The calculated results provide support to the credibility and accuracy of the test method and results. 


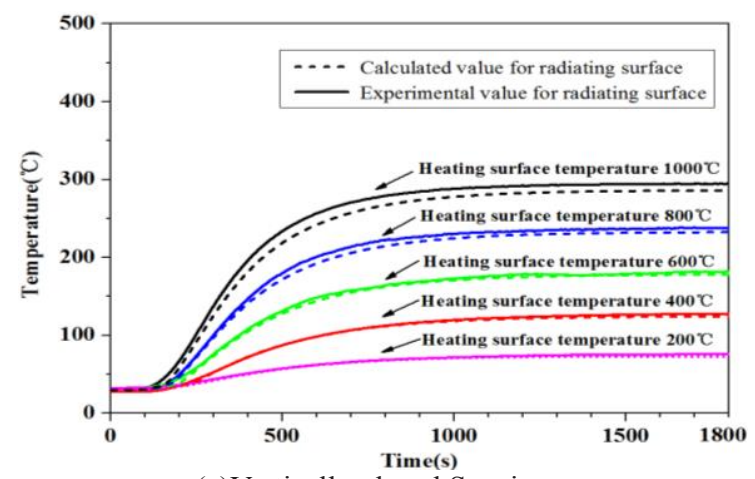

(a)Vertically placed Specimen

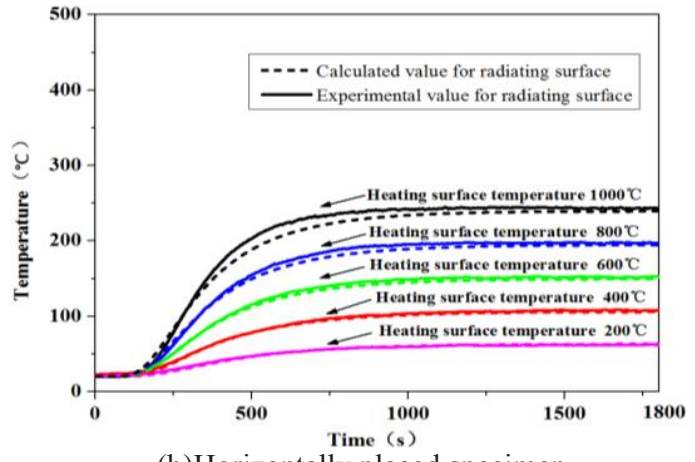

(b)Horizontally placed specimen (radiating surface facing up)

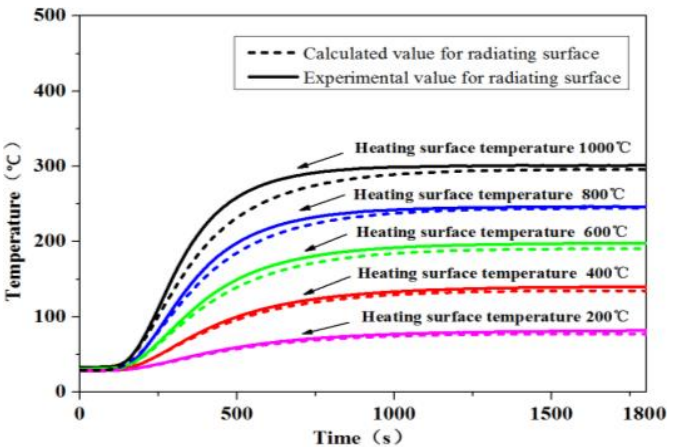

(c) Horizontally placed specimen (radiating surface facing down)

Figure 10. Calculated and experimental radiating surface temperature curves

Table 5. Calculated value, experimental value and relative error of the radiating surface temperature when the light-weight ceramic plate was vertically placed

\begin{tabular}{lcccccccc}
\hline & Time $/ \mathrm{s}$ & 0 & 300 & 600 & 900 & 1200 & 1500 & 1800 \\
\hline Heating & Experimental value $/{ }^{\circ} \mathrm{C}$ & 30.5 & 137.3 & 256.6 & 284.7 & 292.1 & 294.1 & 294.6 \\
surface & Calculated value $/{ }^{\circ} \mathrm{C}$ & 30.0 & 133.6 & 246.1 & 276.0 & 284.1 & 286.0 & 286.2 \\
$1000^{\circ} \mathrm{C}$ & Relative error $/ \%$ & 1.6 & 2.7 & 4.1 & 3.1 & 2.7 & 2.8 & 2.9 \\
\hline Heating & Experimental value $/{ }^{\circ} \mathrm{C}$ & 27.8 & 100.1 & 200.8 & 226.7 & 233.7 & 236.7 & 238.1 \\
surface & Calculated value $/{ }^{\circ} \mathrm{C}$ & 29.0 & 97.6 & 192.5 & 220.6 & 229.1 & 231.7 & 232.5 \\
$800^{\circ} \mathrm{C}$ & Relative error $/ \%$ & 4.3 & 2.5 & 4.1 & 2.7 & 2.0 & 2.1 & 2.4 \\
\hline Heating & Experimental value $/{ }^{\circ} \mathrm{C}$ & 31.5 & 75.6 & 148.2 & 169 & 178.5 & 178.9 & 181.7 \\
surface & Calculated value $/{ }^{\circ} \mathrm{C}$ & 30.0 & 73.9 & 144.2 & 167.5 & 174.9 & 177.3 & 178.1 \\
$600^{\circ} \mathrm{C}$ & Relative error $/ \%$ & 4.8 & 2.2 & 2.7 & 0.9 & 2.0 & 1.2 & 0.9 \\
\hline Heating & Experimental value $/{ }^{\circ} \mathrm{C}$ & 27.8 & 52.8 & 98.6 & 116.7 & 123.5 & 126.4 & 127.7 \\
surface & Calculated value $/{ }^{\circ} \mathrm{C}$ & 29.0 & 52.3 & 98.5 & 115.8 & 121.8 & 123.7 & 124.4 \\
$400^{\circ} \mathrm{C}$ & Relative error $/ \%$ & 4.3 & 0.9 & 0.1 & 0.8 & 1.4 & 2.1 & 2.6 \\
\hline Heating & Experimental value $/{ }^{\circ} \mathrm{C}$ & 31.7 & 43.7 & 62.2 & 70.4 & 73.8 & 75.3 & 76.3 \\
surface & Calculated value $/{ }^{\circ} \mathrm{C}$ & 31.0 & 42.0 & 61.6 & 69.5 & 72.2 & 72.8 & 72.7 \\
$200^{\circ} \mathrm{C}$ & Relative error $/ \%$ & 2.2 & 3.9 & 1.0 & 1.3 & 2.2 & 3.3 & 4.7 \\
\hline
\end{tabular}




\section{Conclusion}

Based on the three different thermal boundary conditions in the thermal insulation experiments of plate materials, the corresponding experimental setups were established. The heat insulation test and numerical simulation were performed for the light-weight ceramic plates at different temperatures. The following conclusions were drawn:

1) In the finite-plane radiation heating tests of thermal insulation materials, under the same heating surface temperature, the radiating surface temperature was the highest when the specimen was placed horizontally with the radiating surface facing down, while the radiating surface temperature was the lowest when the specimen was placed horizontally with the radiating surface facing down When the heating surface temperature was $1,000^{\circ} \mathrm{Cand}$ the time was $1,800 \mathrm{~s}$, the radiating surface temperature of the horizontally placed specimen with the radiating surface facing down was $301.6^{\circ} \mathrm{C}$, while that of the horizontally placed specimen with the radiating surface facing up was $242.2^{\circ} \mathrm{C}$; the relative difference was $19.7 \%$.

2) The radiating surface temperature of the horizontally placed specimen was lower than that of the horizontally placed specimen with the radiating surface facing down. In this experiment, when the heating surface temperature was $1,000^{\circ} \mathrm{C}$ and the time was $1,800 \mathrm{~s}$, the radiating surface temperature of the vertically placed specimen was $2.3 \%$ lower than that of the horizontally placed specimen with the radiating surface facing down.

3) The numerical calculation results agreed very well with experimental results, confirming the credibility and accuracy of the experimental results.

The heat insulation results of the light-weight ceramic materials obtained under different boundary conditions in the present paper will provide valuable guidance for designers in their analysis of the temperature distribution inside the large cabins of high-speed flight vehicles and the final thermal test plan.

\section{Acknowledgment}

The authors appreciate the support from the National Natural Science Foundation of China (No. 11427802).

\section{References}

1. J. Sun, Z. Hu, J. Li, H. Zhang, C. Sun, Ceram. Int. 40, 11787 (2014)

2. J. Li, Z. Hu, X. Wang, J. Yang, C. Sun, Ceram. Int. 43, 8343 (2017)

3. A .R. Figueiredo, J.J. Costa, Int. J. Heat Mass Transfer. 47, 11(2003)

4. Y. Chen, D. Gao, X. Wang, PTCA. A 39, 234 (2003)

5. Q. Qin, J. Jiang, Z. Cheng, E. Jia, Q. He, Aircraft. D. 36, 41 (2016)

6. M. Hanao, J. Japan Society powder powder Metall. 55, 732 (2008)

7. D. Wu, L. Zheng, B. Pan, Y. Wang, B. Sun, M. Mu, Chin. J. Theor. Mech. 44, 297 (2017)

8. W. Yuen, G. Cunnington, Aiaa Aero. Sci. Meeting Exhibit, 737 (2006)

9. D. Wu, L. Shang, Y. Pu, H. Wang, Z. Gao, Spacecraft Environ. Eng. 33, 7 (2016)

10. D. Wu, Y. Wang, Z. Gao, J. Yang, J. Mater. Eng. Perf. 24, 3373 (2015)

11. W. Wang, Z. He, M. Huang, Y. Hu, Z. Wang, Ceram. Int. 43, 38 (2016)

12. D. Wu, B. Pan, Z. Gao, M. Mu, L. Zhu, Y. Wang, J. Exp.Mech. 27, 255 (2012)

13. S. Yang, W. Tao, Heat Transfer 3th ed, 269 (1998)

14. F. Incropera, D. Dewitt, Fundamen. Heat Mass Transfer. 430 (2002)

15. J. Holman, Heat transfer, 285 (2002) 